\title{
White Twitter: Tracing the evolution of the alt-right in retweets, 2009-2016
}

\author{
Saif Shahin \\ American University \\ shahin@american.edu
}

\begin{abstract}
The alt-right White Nationalist movement, which emerged in response to the election of America's first Black president, adopted Twitter from the outset. Tracing its evolution over eight years in retweets, our study suggests that the movement was relatively small and factionalized until 2015-but its subgroups closed ranks following Donald Trump's candidacy and became a blowhorn for his campaign. Integrating social network theory with the emerging view of race and politics as dynamic processes, our study advances a "technosocial" understanding of White Nationalism and its journey from the fringes to the center stage of American politics.
\end{abstract}

\section{Introduction}

In the middle of August 2016, as he trailed Hillary Clinton in opinion polls nationally as well as in key battleground states, Donald Trump decided to hire Steve Bannon, editor of Brietbart News, as the chief executive of his campaign to become the 45th U.S. president. Within a week, a strange-sounding term began to spike in Google Search: "alt-right." Not too long ago, Bannon had called his conservative website-an avid mouthpiece for Trump and his racially tinged populism - "the platform for the alt-right" [1].

But it wasn't until Bannon's elevation from cheerleader to CEO that "alt-right" registered a seismic jump in Google Trends, which tracks the frequency of Google search keywords [2]. Suddenly, it seemed as if everyone was talking about it. But the term wasn't all that new-nor was the phenomenon it represented. It was coined almost eight years earlier, in a speech delivered by conservative iconoclast Paul Gottfried to the H.L. Mencken Club's annual meeting, titled "The Decline and Rise of the Alternative Right" [3]. The dates of this meeting are revealing: November 21-23, 2008, or two weeks after the United States elected its first Black president in Barack Obama. Gottfried

\author{
Yee Man Margaret Ng \\ University of Illinois Urbana-Champaign \\ margaretnym@gmail.com
}

blamed the George W. Bush-era "neo"conservatives for abandoning traditional conservative values and paving the way for Obama, and called for "an attempt to put together an independent intellectual Right, one that exists without movement establishment funding and is also full of young thinkers and activists" (para. 1).

The idea caught on. A stream of young and not-so-young thinkers and activists started to close ranks around the nebulous agenda of reviving old-school conservatism-an "alt-right" that was simultaneously American, Christian, and White in orientation [4]. They dreamed the revanchist dream of a pristine nation, free from Muslims and Jews and Hispanics and immigrants of other hues, and yearned for a "tough leader" who would shun the political correctness of establishment conservatives and blithely embrace a masculine White identity [5]. When Trump burst on the political firmament in 2015 and lay claim to the Republican Party candidature for presidency, he was ridiculed by most other Republicans as well as the mainstream media. No one seemed to take him seriously. But the alt-right-perhaps more appropriately called White Nationalists-was the constituency he championed; they adopted him and ultimately helped him not only trounce his Republican rivals in the party primaries but also win the presidency in 2016.

The emergence of the alt-right reflects and reinforces three "great divides" in American society. One is the well-known conservative versus liberal divide, which has been there for a long time but has taken on a sharper edge because of the success of White Nationalists. The second is the divide within the conservative ranks, between the so-called "neo"conservatives of the Bush era and the alt-right "paleo"conservatives who want to return to what they perceive as traditional conservative values. The third is the divide(s) within the alt-right itself. The movement is not a monolith but a medley of subgroups such as the Ku Klux Klan, the Nazis, the Neo-confederates, and followers of significant leaders such as Dr. David Duke, a former KKK "grand wizard" as well as an ex-Congressman [6]. 
This last divide is the least understood or documented-and therefore the focus of our empirical analysis. We start with the assumption that these divides are not simply ideological but "technosocial"- - shaped by social forces such as politics and race as well as the affordances of information and communication technologies. Therefore, our study traces the evolution of White Nationalism on Twitter - a microblogging platform not only favored by Trump [7] but where the alt-right has been active since its inception [8]. We focus on an eight-year period, beginning with the emergence of the movement itself in the earliest days of the Obama presidency in 2009 and going all the way through 2016.

Specifically, we examine the growth of alt-right subgroups and the movement overall in retweets-or repostings of a Twitter user's post by other users, which are widely recognized as a means of group formation [9, 10]. Adopting a longitudinal design, we identify the moments in time at which retweets grew sizeably. This enables us to distinguish the contextual reasons for the movement's evolution. Next, we examine the evolving structure of the White Nationalist social network and changes in the propensity of different subgroups to retweet each other over time. This allows us to explain how social phenomena such as politics and race-viewed as the social "processes" of polarization and racialization, respectively $[11,12]$ —interacted with technological affordances such as retweeting and the constitution of "weak" and "strong" network ties [13, 14] to push White Nationalism from the fringes to the center stage of American politics.

\section{Polarization on Twitter}

Scholarship on the socio-political impact of digital technologies often draws on the ideal of the Habermasian public sphere, hailing the internet in general and social networking sites (SNSs) like Twitter in particular as positive influences on both representational and direct forms of democracy $[15,16]$. But this liberal-idealist view has come to be challenged [17]. A growing body of research suggests that instead of an open network of individuals sharing ideas freely and engaging in rational deliberations, SNSs are in fact a confederation of small, self-contained bubbles- "echo chambers"-within which homogeneous members speak with and listen to each other [18]. These echo chambers are often based on partisan or ideological affiliations-liberal or conservative-and serve to reinforce their members' limited worldviews. Thus, even as SNSs boost political participation, they also entrench political polarization-indeed, polarization is a key factor predicting participation online [19].
Research focusing on how online self-expression influences the "expressers" themselves_rather than their audience-also bolsters this contention. As Cho and colleagues found, political expressions on SNS “(a) reinforce the expressers' partisan thought process and (b) harden their pre-existing political preferences" [20].

Polarization is neither a new phenomenon nor limited to SNSs. The theory of homophily has long suggested that human beings tend to connect with others like themselves and selectively expose themselves to information that reinforces their worldviews [21]. But SNSs may have exacerbated this tendency [22]. Importantly, online echo chambers don't simply exist to the left- or right-of-center-they come into being toward the far ends of the political spectrum. Twitter, in particular, has become closely associated with political polarization. Leaders espousing extreme ideological positions were among the earliest adopters of Twitter [23]. Such politicians tend to have significantly more Twitter followers [24]. They are also more successful at raising campaign funds on Twitter than their moderate peers [25]. In addition, polarized members tend to dominate Twitter "and are responsible for the majority of tweets received overall due to their popularity and activity" [26].

Social psychologists have argued that conservatives are more likely than liberals to be polarized and drift toward extreme ideological positions - on account of their deeper need to reduce threat and existential uncertainty [27]. Research on SNS-based echo chambers also supports this view [28]. Barber and colleagues' [29] "big data" analysis of nearly 150 million tweets about 12 political and nonpolitical issues revealed that "liberals are significantly more likely than conservatives to participate in cross-ideological dissemination" of information (p. 10). Also, conservative polarization is more likely to happen in retweet networks-or networks formed when Twitter users repost other users' messages - than mention networks, formed when users simply mention each other's Twitter handles in their posts [9].

\section{Racialization on Twitter}

The virtual was once heralded as freedom from the confines imposed by the physical-the "ultimate flight from the body cage" [30] (p. 271). But that view no longer sustains. Body color, in particular, has remained an inescapable feature of virtual reality. No other phenomenon illustrates this better than the so-called "Black Twitter." The notion that Blackness had something to do with Twitter started with a Pew study [31] that came out just three years after the 
platform's launch in 2006. It noted that 26 percent of African-Americans who were online were already using Twitter, compared with 18 percent Hispanics and 19 percent Whites. Soon, a spate of media articles popularized the idea of "Black Twitter"-arguing that Blacks didn't just use Twitter more, but they also used it unlike anyone else. As Manjoo [32] explained, "They form tighter clusters on the network-they follow one another more readily, they retweet each other more often, and more of their posts are @-replies-posts directed at other users" (para. 6).

Most descriptions of Black Twitter treat Blackness as an a priori identity that "Black people" already possess, and that leads them to use Twitter in a certain way. But such a view "largely ignores the properties of the networked online environment that Black users act in" [33] (p. 52). Instead, Sharma [33] argues for a "technosocial" approach to understanding Black Twitter, which does not ignore the "materiality" of offline Black bodies but also pays attention to the materiality of digital technologies, imposed through the manner in which their algorithms operate. In this approach, digital technologies such as SNSs don't simply reflect or replicate extant racial categories. Instead, they "generate" race by producing the identities of subjects in and through interactive action. This technosocial view coheres with the idea of racialization, or "the changing meanings of race within different political, social, and economic contexts, producing a more expansive and complex discussion of race" [12] (p. 648). Racialization departs from race as a static phenomenon and focuses instead on the social process by which racial identities as well as their meanings and power asymmetries come into being [11].

Many cultural critics have also questioned the surfeit of media and academic attention to Black Twitter, noting that it reinforces Blackness as a "deviant" identity-in contrast to Whiteness, which is deemed "normal" and therefore in no need of scrutiny [34]. This is indeed a long-standing concern in race and ethnic studies, where " 'White' is a relatively uncharted territory that has remained invisible as it continues to influence the identity of those both within and without its domain" [35] (p. 291). In recent years, more scholars have started putting Whiteness under the scanner to understand what it means and how these meanings come into being [36].

Lyubansky [37] identified three components of Whiteness in the American context-racial identity, racial bias, and racial privilege. As a racial identity, Whiteness is often unnoticed, especially by White people themselves, who "much more strongly prefer to identify as 'American' or as a humanist than as "white" (para. 4). Nonetheless, a number of psychological implicit association tests have showed that White people exhibit "unconscious (and therefore unintentional) bias in favor of those who are white, a bias that is either not evident or significantly smaller, in non-white groups" (para. 5; see also [38]). Finally, Whiteness comes along with a range of privileges, in particular "the privilege to assume that whiteness is the norm against which everyone else should be compared" (para. 6). These features suggest that even though White Nationalism may be relatively new as an explicit political ideology, the implicit conflation of Whiteness with nationalism as a social identification-an example of racialization - isn't all that new and is, in fact, deeply pervasive in American society.

In a study of online extremism, Berger [6] reported an explosion of White Nationalism on Twitter. Driven by the fear of White genocide, or the notion that the "White race" is directly endangered by the increasing diversity of American society-it has added tens of thousands of followers in the past few years. It was also "heavily invested in Donald Trump's presidential campaign," with "Trump-related hashtags outperform[ing] every white nationalist hashtag except for whitegenocide" (p. 3). Berger's report was based on the analysis of more than 25,000 accounts that were followers of 18 "seed" accounts of White Nationalists-identified by the author's own research as well as data from the Anti-Defamation League and Southern Poverty Law Center. Berger also found White Nationalists on Twitter to be heavily factionalized and classified the seed accounts into six subgroups: $K u$ Klux Klan; Nazi; Neo-Confederate; Significant Leaders; Other Ideologies; and Other Institutions.

\section{Ties, Clusters, and Networks}

In this study, we examine White Nationalism as a technosocial phenomenon and trace its evolution on Twitter to identify particular social and technical factors that led to its diffusion. To do so, we integrate the recent research on polarization and racialization online with ideas from social network theory. Social networks are comprised of dyadic relationships, or ties, between individual members, also known as nodes. Together, the ties provide the network with an overarching structure. Ties between members differ by their "strength"- defined as the "combination of the amount of time, the emotional intensity, the intimacy (mutual confidence), and the reciprocal services which characterize the tie" [13] (p. 1361). On Twitter, for instance, people who often reply to, mention, or retweet each other have a strong tie, while those who do so infrequently have a weak tie. In any large network, there 
is often a fair mix of strong and weak ties. Members who have strong ties with each other form clusters, or closely-interconnected groups within the network, which are linked to other such groups through weak ties between a few members across groups. As a result, strong ties are also called "bonding ties" while weak ties are known as "bridging ties" because they bridge the distance across groups in a network.

The structure of the network influences how information or collective behavior diffuses across it. Scholars have argued that people with strong ties tend to be quite similar and therefore don't have anything new to share with each other. Such ties are therefore "redundant." On the other hand, people with weak ties are often dissimilar in their behaviors and the kinds of information they are able to share. That means weak ties can help "new" information quickly disseminate across a network-information that arrives in one cluster of the network can travel to other clusters through these bridging ties and diffuse across the network. According to Granovetter [13], "whatever is to be diffused can reach a larger number of people, and traverse a greater social distance, when passed through weak ties rather than strong" (p. 1366). A number of later studies have supported this theory, known as the strength of weak ties [39]. Watts and Strogatz [40] showed that even a small percentage of weak ties is sufficient to make information and collective behaviors disseminate across a network.

Some studies have, however, also found that while weak ties are important for individuals to be exposed to new information, it is the strong and so-called "redundant" ties that better predict the propensity to share information-especially via retweets [10]. These studies imply that Twitter users don't only-or even typically-share information because it is new. Instead, other motivations are at play. As Harrigan and colleagues [10] concluded, "individuals within a community tend to be similar ... thus increasing the relevance of, and attention paid to, each other's messages" (p. 478). "Redundant" information from like-minded tweeters may be more commonly retweeted within community structures because its very redundancy allows Twitter users to reinforce community bonds and signal their identification with other members of the community.

The dynamics of networked action thus closely resemble the sociopolitical processes of polarization and racialization - specifically the act of sharing information from particular sources, or retweeting, as a means of locating oneself within particular ideological/racial subgroups or clusters. A close scrutiny of the evolution of the White Nationalist retweet network, which pays attention to the changing patterns of retweeting activity over time as well as changes in the structural features of the retweet network, can therefore reveal how and why the "alt-right" became a significant political force in the run up to the 2016 election and helped Donald Trump become president. To guide our inquiry, we propose the following research questions:

RQ1a: How did the retweet frequencies of alt-right posts change over time?

RQ1b: How did the retweet frequencies of alt-right subgroups change over time?

RQ2a: How did the alt-right retweet network change over time?

RQ2b: How did cross-retweets of alt-right subgroups change over time?

\section{Method}

Our point of departure was Berger's [6] classification of 18 "seed" White Nationalist accounts into six subgroups: Ku Klux Klan (@ukanw, @ukasouthfla, @kkkofficial311); Nazi (@nsm88, @anp14, @nsfm_commander, @natall_adv); Neo-Confederate@ (@ixienetdotorg, @cofcc76, @ occdissent); Significant Leaders (@drdavidduke, @ whitakeronline); Other Ideologies (@ nationsaryan, @ tcmchurch, @creatoralliance); and Other Institutions (@nwfront, @stormfrontwpww, @american3rdp). All public retweets of the original tweets from these seed accounts, posted over an eight-year period-January 1, 2009 to December 31, 2016-were collected through Twitter's Firehose. The Firehose provides access to 100 percent of Twitter data published over a specified time period, as opposed to Twitter's search and streaming APIs that only provide limited access [41]. Retweets were captured using the patented algorithmic technology of Crimson Hexagon's platform. We used boyd, Golder, and Lotan's [42] rubric for determining retweets ('RT: @', 'retweet @', 'retweeting @', ‘(via @)', 'RT (via@)', 'thx @', 'HT @', and 'r @'). In total, 321,718 retweets were collected (see Table 1).

After mining the data, we relied on social network analysis and primary duplication to test our hypotheses. Social network analysis is not a specific method but "a loose federation of approaches" to study patterns of relations among social actors (Burt, 1980). We followed Shumate and colleagues' [43] "relational, systemic, and contextual" approach to social network analysis, which steps away from agent-centric approaches and focuses instead on illustrating and explaining emergent patterns of social structures (for a discussion of different approaches, see [44]. Each tweet was coded as an arc with the seed account as the "target" and any tweeter who retweeted a seed account's tweet as the 
Table 1. Retweet Frequency

\begin{tabular}{|c|c|c|c|c|c|c|c|c|c|}
\hline & 2009 & 2010 & 2011 & 2012 & 2013 & 2014 & 2015 & 2016 & Total per account \\
\hline Ku Klux Klan & & & & 668 & 105 & 18 & 14 & 74 & 879 \\
\hline kkkofficial311 & & & & - & - & - & 2 & 72 & 74 \\
\hline ukanw & & & & 588 & 63 & - & 2 & - & 653 \\
\hline ukasouthfla & & & & 80 & 42 & 18 & 10 & 2 & 152 \\
\hline Nazi & & 15 & 845 & 1,591 & 2,643 & 3,578 & 3,786 & 5,477 & 17,935 \\
\hline apn14 & & 6 & 837 & 1,540 & 2,284 & 3,570 & 3,500 & 4,702 & 16,439 \\
\hline nsm88 & & 9 & 7 & 8 & 6 & 8 & 285 & 775 & 1,098 \\
\hline nsfm_commander & & - & 1 & 43 & 353 & - & - & - & 397 \\
\hline natall_adv & & & & & & & 1 & & 1 \\
\hline Neo-Confederate & & 98 & 264 & 3,543 & 6,746 & 7,303 & 9,785 & 20,937 & 48,676 \\
\hline $\operatorname{cofcc} 76$ & & - & 156 & 1,699 & 5,148 & 5,642 & 5,498 & 790 & 18,933 \\
\hline dicienetdotorg & & - & 1 & - & - & 2 & 3 & 8 & 14 \\
\hline occdissent & & 98 & 107 & 1,844 & 1,598 & 1,659 & 4,284 & 20,139 & 29,729 \\
\hline Significant Leaders & & 4 & 36 & 203 & 215 & 2,085 & 11,144 & 230,235 & 243,922 \\
\hline whitakeronline & & 2 & 20 & 203 & 213 & 153 & 213 & 195 & 999 \\
\hline drdavidduke & & 2 & 16 & - & 2 & 1,932 & 10,931 & 230,040 & 242,923 \\
\hline Other Ideologies & & 2 & - & 46 & 195 & 84 & 1,239 & 937 & 2,503 \\
\hline CreatorAlliance & & - & - & 40 & 191 & 81 & 1,231 & 929 & 2,472 \\
\hline nationsaryan & & - & - & 6 & 4 & - & 6 & 8 & 24 \\
\hline tcmchurch & & 2 & - & - & - & 3 & 2 & & 7 \\
\hline Other Institutions & 59 & 421 & 3,150 & 214 & 875 & 799 & 1,312 & 973 & 7,803 \\
\hline american3rdp & - & - & - & 148 & 794 & 711 & 1,195 & 893 & 3,741 \\
\hline nwfront & - & 5 & 12 & 16 & 31 & 20 & 21 & 29 & 134 \\
\hline stormfrontwpww & 59 & 416 & 3,138 & 50 & 50 & 68 & 96 & 51 & 3,928 \\
\hline Total per year & 59 & 540 & 4,295 & 6,265 & 10,779 & 13,867 & 27,280 & 258,633 & 321,718 \\
\hline
\end{tabular}

"source." Most seed accounts had not come online until 2012 and the frequency of retweets was also fairly low until then. Therefore, we focused our social network analysis on the 2012-2016 period. Five bipartite network graphs - one for each year-with two kinds of vertices - seed accounts and retweeters - were generated. We used the statistical program $\mathrm{R}$ and network visualization tool Gephi for the analysis.

While social network analysis allowed us to visualize the network as a whole and understand its clustered structure based on the extent of retweets within clusters, primary duplication helped us measure the precise degree of retweeting between seed categories. The idea of primary duplication is borrowed from media audience studies. It is meant to analyze the extent to which an audience member who consumes one media outlet also consumes a second outlet [45]. Its earliest application was Webster's [46] study of subsets of television programs watched by the same set of audience members. We used this concept to illustrate the extent to which a Twitter user who retweets one seed category $i$ also retweets a second seed category $j$, where the row is defined as $i$ and the column as $j$ (see Tables 2a-2e). To conduct primary duplication, bipartite networks were converted into a whole network with the seed accounts as nodes and shared retweeters as edges. When using primary duplication, it is important to remember which category is treated as $i$ and which as $j$ - as the proportion of $i$ retweeters who also retweet $j$ need not be the same as the proportion of $\mathrm{j}$ retweeters who retweet $i$ [47].

\section{Results}

\subsection{Retweet Frequencies}

Our first research question (RQ1a) focused on tracing the overall trajectory of White Nationalist retweets over time. A year-by-year frequency analysis showed that the retweets of messages originally posted by the 18 seed accounts grew exponentially-from 59 in 2009 to 258,633 in 2016 (see Table 1). While retweet numbers increased every year, they spurted sharply in 2015 (197 percent from the preceding year) before exploding in 2016 (948 percent). This growth is partly explained by the increasing numbers of seed accounts. Only one seed account_-@stormfrontwpww, belonging to an organization called Stormfront with the slogan "White Pride World Wide" was active in 2009. But more seed accounts came online in the next three years and 15 were active by 2012. The number of tweets posted by these accounts also grew accordingly, thus providing many more tweets that could be retweeted. The growth in retweets also coincides with Trump's presidential campaign, which was launched mid-year in 2015 and scored one victory after another, culminating 
with his election in November 2016.

Analyzing retweets at the level of subgroups (RQ1b) revealed more nuanced patterns. Not all the subgroups grew similarly or simultaneously. Ku Klux Klan's retweet numbers were the highest in 2012, the year in which two of its three seed accounts came online, but then they began to decline. Two more subgroups-Other Ideologies and Other Institutions-witnessed both ups and downs in retweets over these years. But the three remaining subgroups-Nazis, Neo-confederates, and Significant Leaders-enjoyed steady growth from 2010, when most of their accounts came online, through 2016.

We also found sharp differences in the retweeting fortunes of accounts that made up these subgroups. Two patterns in particular stand out. First, retweets of messages posted by a single account under Significant Leaders-@ drdavidduke, belonging to Dr. David Duke, a former KKK "grand wizard" and ex-Congressman-effectively drove the spurts in 2015 and 2016, growing year-on-year by 566 percent and 2,104 percent respectively. Second, 2012 was a pivotal moment for the movement. The overall growth of retweets this year was a modest 146 percent. But if we excluded the retweets of a single account-@ @stormfrontwpww, which was quite popular in 2011 but whose retweets dwindled dramatically after that - then year-on-year growth in 2012 was a much higher 537 percent.

The analysis of retweet frequencies leads us to some interesting insights, especially when viewed alongside "offline" political and social developments. First, while the alt-right movement started at the end of 2008 as a reaction to President Obama's election [3], it remained relatively nascent in the first few years. But the prospect of Obama's re-election in 2012 appears to have given the movement another jolt of life-both online and offline. As our analysis shows, this was the year a number of seed alt-right accounts became active and retweet activity jumped more than five times (after excluding @ stormfrontwpww). Interestingly, this was also the year when Trayvon Martin, a Black teenager in Sanford, Florida, was gunned down by George Zimmerman-the first of a series of high-profile shootings of Black youths by White police officers and vigilantes across the United States leading up to the 2016 election.

Second, even as the White Nationalist ideology kept growing through the years, it was searching for a political leader who would adopt its bigoted stance without worrying about political correctness. No such leader emerged in 2012, and White Nationalists had to wait for someone like Trump to arrive on the scene. His campaign and eventual nomination came as a shot in the arm for their ideology, as evident in the spurts in their retweet frequencies in 2015 and 2016. This implies that Trump was able to tap into an ideology that was already deeply entrenched. In other words, Trump didn't create White Nationalism as is sometimes assumed - although he clearly helped bring it from the fringes to the mainstream.

Third, the White Nationalist ideology has multiple strains and not all of them became equally popular online. Nazi and Neo-confederate seed accounts enjoyed continuous growth, as did one of the Significant Leaders, Dr. David Duke. Meanwhile, the Ku Klux Klan's retweet frequencies declined. This suggests that while White Nationalism is often viewed from the outside as a single cohesive movement, there are sharp divisions within and these divisions matter to their followers.

\subsection{Retweet Network and Cross-Cluster Retweets}

We next asked how the network constituted by retweets of White Nationalist seed accounts changed over time (RQ2a). As only a few of the seed accounts had come online by 2011 and retweeting was relatively low, social network analysis focused on the period of 2012 through 2016. It was supplemented by primary duplication, which yielded precise measurements of cross-cluster retweets (RQ2b) and enabled us to better understand the reasons behind the evolving structure of the network. We found that the network went through three stages in this period.

Polarized Crowds. Two clusters representing two White Nationalist subgroups-Nazis and Neo-confederates-dominated the network in 2012 and 2013 - as evident from the size of their names (Figure 1). Although these clusters were connected with other White Nationalist clusters and were thus part of the same overall social network, there were very few ties between these two. At this stage, the White Nationalist network resembled what Smith and colleagues [48] called "polarized crowds" in their typology of Twitter networks - comprising two big and dense clusters that are mostly disconnected from each other and rely on distinct sources for information. Primary duplication showed that in 2012 and 2013, mid to high percentages of Nazi retweeters retweeted posts from most other subgroups except the Neo-confederates (Table 2a, 2b). Conversely, mid to high percentages of Neo-confederate retweeters also retweeted the messages of most other subgroups-except Nazis. Interestingly, the Nazis and Neo-confederates were not retweeted nearly as much by other subgroups. Their dominance in this period was, therefore, driven by their retweeters' proclivity to 
retweet other subgroups.

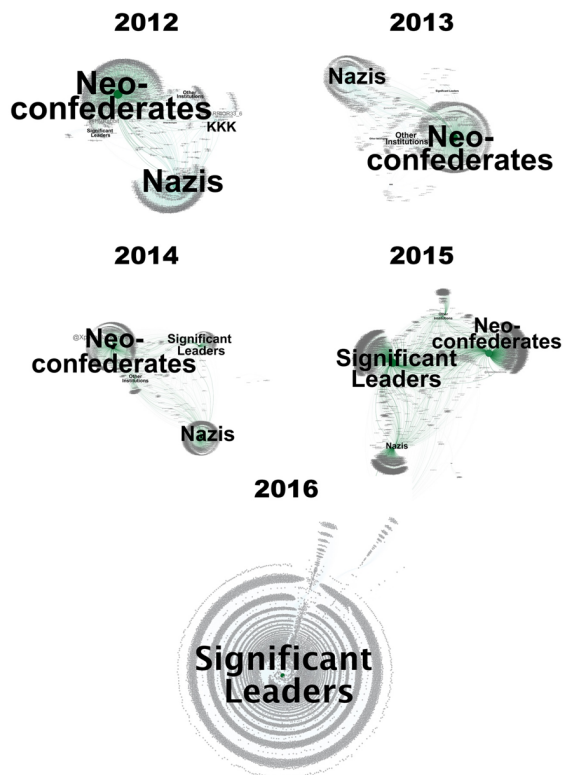

Figure 1. Changing structure of the alt-right Twitter network.

Community Clusters. The network structure changed in 2014 with the emergence of Significant Leaders as a third major cluster, which continued to grow and rivaled the dominance of the Nazi and Neo-confederate clusters in 2015. In these two years, the network took the form of "community clusters," comprising multiple subgroups that form around a few hubs - each having its own members and sources of information [48]. Such a network illustrates "diverse angles on a subject based on its relevance to different audiences, revealing a diversity of opinion and perspective" (p. 3). Interconnections exist, but are very low compared with the intensity of ties within each cluster. In line with these characteristics, primary duplication revealed an overall drop in cross-cluster retweets in 2014 and 2015 (Tables 2c \& 2d). Nazi and Neo-confederate retweeters' retweets of other subgroups slowed down compared with the previous stage. However, Significant Leaders' retweeters began retweeting other subgroups more, particularly in 2015, contibuting to the subgroup's emergence as a major cluster and transforming the network in the process.

Broadcast Network. The Significant Leaders cluster continued to expand and, in 2016, became the single dominant cluster. Retweets of Nazi and Neo-confederate clusters grew this year as well. But Significant Leaders, specifically the account @ drdavidduke, was retweeted so heavily in 2016 that it effectively turned the network structure into a "broadcast network" - with a single, distinct hub whose tweets were reposted by an overwhelming majority of other members [48]. Such a highly centralized structure, with outward spokes, indicates that the White Nationalist Twitter network effectively functioned as a single-voice megaphone for the Trump campaign in 2016. Primary duplication (Table 2e) indicated that high proportions of retweeters of Significant Leaders were also retweeting other subgroups-explaining this cluster's dominance in the network.

Social network analysis and primary duplication thus reinforce some of the indications of frequency analysis while providing several new insights of their own. First, while Berger [6] classified White Nationalist seed accounts into subgroups based on their self-identification as KKK, Nazi and so on, our study suggests that these identifications have "real" meanings and they influence online interactions among White Nationalists. Retweeting within subgroups is consistently higher than across subgroups, a process that organically creates subgroup-oriented clusters within the White Nationalist social network. Although the clusters do interact, the near-complete absence of cross retweets between Nazis and Neo-confederates-at least until 2015-suggests the two subgroups were sharply polarized. Second, the subgroups-even Nazis and Neo-confederates-were willing to give up their differences and congeal into a strong broadcast network in 2016. Herein lies Trump's true impact on White Nationalism: he managed to unite the alt-right factions into a powerful blowhorn for his candidacy.

\section{Discussion}

We set out to trace the evolution of the alt-right, or White Nationalism, on Twitter between 2009 and 2016 - a period in which it moved from the margins to the center stage of American politics. Specifically, we looked at the diffusion of the movement in retweets. As our empirical analysis indicates, both social and technological forces shaped the movement's evolution. These are closely intertwined and best regarded as "technosocial." Here, we will parse them for closer scrutiny.

First, the social. While Obama's election in 2008 kickstarted White Nationalism as an explicit political ideology — both offline and online [3, 6] —our analysis suggests that the movement's evolution was initially a slow process. There wasn't much activity until 2011. But the prospect of Obama's re-election in 2012 galvanized the movement-again both offline (in the form of high-profile killings of Black youth by White police officers and self-appointed vigilantes) and online 
Table 2a. Simple Primary Duplication Matrix, 2012 (\%)

\begin{tabular}{lllllll}
\hline Variable & Ku Klux Klan & Nazi & Neo-confederate & Significant Leaders & Other Ideologies & Other Institutions \\
\hline KKK & - & 5.17 & 3.75 & 28.57 & 47.37 & 11.50 \\
Nazi & 42.67 & - & 4.72 & 33.33 & 31.58 & 15.04 \\
Neo-conf & 41.33 & 6.30 & - & 61.90 & 63.16 & 32.74 \\
Sig. Leaders & 8.00 & 1.13 & 1.57 & - & 21.05 & 3.54 \\
Other Ideo's & 12.00 & 0.97 & 1.45 & 19.05 & - & 2.65 \\
Other Inst's & 17.33 & 2.75 & 4.47 & 19.05 & 15.79 & - \\
\hline
\end{tabular}

Table 2b. Simple Primary Duplication Matrix, 2013 (\%)

\begin{tabular}{lllllll}
\hline Variable & Ku Klux Klan & Nazi & Neo-confederate & Significant Leaders & Other Ideologies & Other Institutions \\
\hline KKK & - & 1.21 & 0.69 & 2.70 & 10.17 & 4.35 \\
Nazi & 27.27 & - & 5.60 & 10.81 & 44.07 & 35.18 \\
Neo-conf & 25.00 & 8.96 & - & 56.76 & 42.37 & 49.01 \\
Sig. Leaders & 2.27 & 0.40 & 1.32 & - & 3.39 & 8.30 \\
Other Ideo's & 13.64 & 2.62 & 1.57 & 5.41 & - & 9.88 \\
Other Inst's & 15.91 & 3.02 & 7.80 & 32.43 & 23.73 & - \\
\hline
\end{tabular}

(in the form of more White Nationalist accounts going live and retweeting expanding quickly). The movement grew steadily after that. Trump's candidacy came as a shot in the arm for White Nationalists, boosting retweets exponentially in 2015 and 2016.

Our study shows that White Nationalism is a rainbow rather than a cloud, comprising multiple subgroups. These subgroups interact with each other, but they can also be sharply divided-as was the case with Nazis and Neo-confederates, at least until 2015. Trump didn't create White Nationalism, as is sometimes assumed: he tapped into a movement that was already growing as a reaction to Obama's presidency. But Trump's intervention brought White Nationalist subgroups together and fused them into a broadcast network that served as a blowhorn for his candidacy. This structural transformation is perhaps the reason why White Nationalism had such a strong impact on the 2016 election.

Our study also illustrates how racialization and polarization unfold as social processes-interlocking multiple meanings that themselves keep evolving over time. Different subgroups of White Nationalists combined Whiteness and Americanness in different ways. Some were more successful than others. But none remained stagnant. White Nationalism, as a far-right movement, supposes itself to be driven by affixed and absolutist notions of race and nationhood-and that is what it propagates. But in practice, even its own adherents have unstable identities that they constantly negotiate in emerging contexts.

Second, the technical. Our study illustrates the implications of regarding retweeting as identity construction. Racial identification, as Sharma [33] observed, "is discovered in its emergence through connections between bodies, and other entities and processes" (p. 54). Saldanha [49] further explained racialization as "a particular spatiotemporal disciplining and charging" of bodies, which in turn "collectively start behaving like situationally distinct aggregates-racial formations, racial clusters" (p. 190). Retweeting is the algorithmic conduit of such disciplining and charging of bodies.

Furthermore, our analysis demonstrates how the structure of the network bears upon racialization and polarization-and how weak and strong ties play different yet complementary roles in this dynamic process. Weak "bridging" ties allow new meanings of White Nationalism to diffuse across clusters and racialization and polarization to take place over time $[13,39]$. But this process requires two contingent conditions. One, new meanings diffuse across a network only when weak ties exist across all clusters in the network. The absence of weak ties across particular clusters, as was the case between Nazis and Neo-confederates until 2015, can circumvent the process. Two, weak ties are able to diffuse new meanings across a network only when they connect individuals who are embedded within clusters with strong "bonding" ties. Most of the retweeting takes places within such strong-tie clusters despite their high levels of information redundancy, as some previous studies have also found [9, 10]. Thus, both weak and strong ties operate simultaneously and in complementary ways to precipitate racialization and polarization.

The limitations of our study can serve as avenues for future research. First, Berger [6] noted that his list of "seed" White Nationalist accounts, on which we rely, might not be comprehensive. Future research may identify additional seed accounts and incorporate them into the analysis of the White Nationalist network. Second, we have examined the network formed through retweeting-which is not the only form of social interaction afforded by Twitter. Retweets signify endorsement, but interaction through 
Table 2c. Simple Primary Duplication Matrix, 2014 (\%)

\begin{tabular}{lllllll}
\hline Variable & Ku Klux Klan & Nazi & Neo-confederate & Significant Leaders & Other Ideologies & Other Institutions \\
\hline KKK & - & 0.00 & 0.00 & 0.00 & 0.00 & 0.00 \\
Nazi & 0.00 & - & 4.28 & 8.19 & 20.75 & 8.86 \\
Neo-conf & 0.00 & 4.58 & - & 21.42 & 33.96 & 46.20 \\
Sig. Leaders & 0.00 & 2.52 & 6.15 & - & 28.30 & 13.61 \\
Other Ideo's & 0.00 & 0.63 & 0.96 & 2.79 & - & 4.43 \\
Other Inst's & 0.00 & 1.60 & 7.81 & 8.01 & 26.42 & - \\
\hline
\end{tabular}

Table 2d. Simple Primary Duplication Matrix, 2015 (\%)

\begin{tabular}{lllllll}
\hline Variable & Ku Klux Klan & Nazi & Neo-confederate & Significant Leaders & Other Ideologies & Other Institutions \\
\hline KKK & - & 0.22 & 0.08 & 0.12 & 0.00 & 0.00 \\
Nazi & 27.27 & - & 5.81 & 10.02 & 33.94 & 12.24 \\
Neo-conf & 18.18 & 11.12 & - & 19.00 & 33.94 & 42.45 \\
Sig. Leaders & 27.27 & 17.63 & 17.47 & - & 38.53 & 35.95 \\
Other Ideo's & 0.00 & 2.71 & 1.41 & 1.75 & - & 3.44 \\
Other Inst's & 0.00 & 4.68 & 8.49 & 7.82 & 16.51 & - \\
\hline
\end{tabular}

Table 2e. Simple Primary Duplication Matrix, 2016 (\%)

\begin{tabular}{lllllll}
\hline Variable & Ku Klux Klan & Nazi & Neo-confederate & Significant Leaders & Other Ideologies & Other Institutions \\
\hline KKK & - & 0.15 & 0.19 & 0.03 & 0.00 & 0.36 \\
Nazi & 4.35 & - & 2.75 & 0.90 & 19.00 & 10.12 \\
Neo-conf & 20.29 & 10.07 & - & 4.72 & 24.00 & 38.19 \\
Sig. Leaders & 39.13 & 36.44 & 52.15 & - & 64.00 & 59.86 \\
Other Ideo's & 0.00 & 0.95 & 0.33 & 0.08 & - & 1.78 \\
Other Inst's & 2.90 & 2.84 & 2.92 & 0.41 & 10.00 & - \\
\hline
\end{tabular}

"replies" or "mentions" are more complex in their signification. Studying the networks they produce can, for instance, help understand the interaction between White Nationalists and other social groups. Third, closer attention to the content of White Nationalist tweets can help answer new research questions that emerge from our analysis: for instance, why Nazi and Neo-confederate clusters were so sharply divided and why Dr. David Duke (@drdavidduke), in particular, managed to become the hub of the retweet network in 2016. Finally, the key implications of our study-the organic dichotomies within the White Nationalist movement and how they evolved over time-ought to be examined outside of Twitter as well, especially in offline contexts [50].

\section{References}

[1] S. Posner, How Donald Trump's new campaign chief created an online haven for White Nationalists, Mother Jones, 2016. [Online]. Available: http://www.motherjones.com/politics/2016/08/ stephen-bannon-donald-trump-alt-right-breitbart-news

[2] GoogleTrends, n.d. [Online]. Available: https://trends. google.com/trends/explore?q=alt-right

[3] P. Gottfried, The decline and rise of the alternative right, The Unz Review: An Alternative Media Selection website, 2008.

[4] B. Wallace-Wells, Is the alt-right for real?, The New Yorker, 2016. [Online]. Available: http://www.newyorker.com/news/ benjamin-wallace-wells/is-the-alt-right-for-real

[5] A. Popkova, "Putin is playing chess and i think we are playing marbles. Vladimir Putins soft power and the
American Right," International Communication Gazette, vol. 79, no. 5, pp. 437-458, 2017.

[6] J. M. Berger, Nazis vs. ISIS on Twitter: A comparative study of White Nationalist and ISIS online social media networks, 2016. [Online]. Available: https://cchs.gwu.edu/files/downloads/Nazis\% 2520v.\%2520ISIS\%2520Final_0.pdf

[7] R. McCormick, Donald Trump says Facebook and Twitter helped him win, The Verge, 2016. [Online]. Available: https://www.theverge.com/2016/11/ 13/13619148/trump-facebook-twitter-helped-win

[8] B. Kharakh and D. Primack, Donald Trumps social media ties to White Supremacists, Fortune, 2016. [Online]. Available: http://fortune.com/ donald-trump-white-supremacist-genocide/

[9] M. Conover, J. Ratkiewicz, M. Francisco, B. Goncalves, F. Menczer, and A. Flammini, Political Polarization on Twitter, Proceedings of International AAAI Conference on Web and Social Media, 2011.

[10] "Influentials, novelty, and social contagion: The viral power of average friends, close communities, and old news," Social Networks, vol. 34, no. 4, pp. $470-480$, 2012 .

[11] M. Omi and H. Winant, Racial formation in the United States: From the 1960s to the 1980s. 2nd edition. New York: Routledge, 1994.

[12] S. Selod and D. G. Embrick, "Racialization and muslims: Situating the muslim experience in race scholarship," Sociology Compass, vol. 7, no. 8, pp. 644-655.

[13] M. S. Granovetter, "The strength of weak ties," American Journal of Sociology, vol. 78, no. 6, pp. 1360-1380, 1973.

[14] D. Centola and M. Macy, "Complex contagions and the weakness of long ties," American Journal of Sociology, vol. 113, no. 702-734, 2007.

[15] W. L. Bennett and A. Segerberg, "The logic of connective action," Information, Communication \& Society, vol. 15, no. 5, pp. 739-768, 2012. 
[16] Z. A. Papacharissi, A private sphere: Democracy in a digital age. Cambridge: Polity, 2010.

[17] A. Smidi and S. Shahin, "Social media and social mobilisation in the middle east: A survey of research on the arab spring," India Quarterly, vol. 73, no. 2, pp. 196-209, 2017.

[18] C. R. Sunstein, Going to extremes. New York: Oxford University Press, 2009.

[19] "Stumbling upon news on the internet: Effects of incidental news exposure and relative entertainment use on political engagement," Computers in Human Behavior, vol. 29, no. 6, pp. 2607 - 2614, 2013.

[20] J. L. Gibbs, H. Kim, and S. Ki, "Investigating the role of control and support mechanisms in members sense of virtual community," Communication Research, vol. 46, no. 1, pp. 117-145, 2019.

[21] M. McPherson, L. Smith-Lovin, and J. M. Cook, "Birds of a feather: Homophily in social networks," Annual Review of Sociology, vol. 27, no. 1, pp. 415-444, 2001.

[22] C. Fuchs, Social media: A critical introduction. London: Sage, 2013.

[23] J. R. Straus, M. E. Glassman, C. J. Shogan, and S. N. Smelcer, "Communicating in 140 characters or less: Congressional adoption of twitter in the 111th congress," PS: Political Science amp; Politics, vol. 46, no. 1, p. 6066, 2013.

[24] "Political polarization on twitter: Implications for the use of social media in digital governments," Government Information Quarterly, vol. 33, no. 4, pp. 777 - 782, 2016.

[25] "Who benefits from twitter? social media and political competition in the u.s. house of representatives,' Government Information Quarterly, vol. 30, no. 4, pp. $464-472,2013$.

[26] J. Shore, J. Baek, and C. Dellarocas, Network structure and patterns of information diversity on Twitter, Social Science Research Network, 2016. [Online]. Available: https://papers.ssrn.com/sol3/papers. cfm?abstract_id=2813342

[27] D. O. Sears and J. L. Freedman, "Selective exposure to information: A critical review," Public Opinion Quarterly, vol. 31, no. 2, pp. 194-213, 1967.

[28] E. Colleoni, A. Rozza, and A. Arvidsson, "Echo chamber or public sphere? predicting political orientation and measuring political homophily in twitter using big data," Journal of Communication, vol. 64, no. 2, pp. 317-332.

[29] P. Barber, J. T. Jost, J. Nagler, J. A. Tucker, and R. Bonneau, "Tweeting from left to right," Psychological Science, vol. 26, no. 10, pp. 1531-1542, 2015.

[30] T. Terranova, "Post-human unbounded: Artificial evolution and high-tech subcultures," in The Cybercultures reader, D. Bell and B. Kennedy, Eds. London: Routledge., 2000, p. 268279.

[31] S. Fox, K. Zickuhr, and A. Smith, Twitter and status updating, Pew Internet \& American Life Project, 2009. [Online]. Available: http://www.pewinternet.org/Reports/2009/ 17-Twitter-and-Status-Updating-Fall-2009.aspx

[32] F. Manjoo, How Black people use Twitter, Slate, 2010. [Online]. Available: http://www.slate.com/articles/technology/ technology/2010/08/how_black_people_use_twitter.html
[33] S. Sharma, "Black twitter?: Racial hashtags, networks and contagion," New Formations, vol. 78, pp. 46-64, 2013.

[34] A. Brock, "From the blackhand side: Twitter as a cultural conversation," Journal of Broadcasting \& Electronic Media, vol. 56, no. 4, pp. 529-549, 2012.

[35] T. K. Nakayama and R. L. Krizek, "Whiteness: A strategic rhetoric," Quarterly Journal of Speech, vol. 81, no. 3, pp. 291-309, 1995.

[36] J. Feagin, The white racial frame. New York, NY: Routledge, 2010.

[37] M. Lyubansky, The meaning of Whiteness, Psychology Today, 2011. [Online]. Available: http://www.psychologytoday.com/blog/ between-the-lines/201112/the-meaning-whiteness

[38] M. Banaji and A. G. Greenwald, Blindspot: Hidden biases of good people. New York: Bantam Books, 2016.

[39] R. S. Burt, "Models of network structure," Annual Review of Sociology, vol. 6, no. 1, pp. 79-141, 1980.

[40] D. J. Watts and S. H. Strogatz, "Collective dynamics of 'small-world' networks," Nature, no. 6684, pp. 440-442, Jun.

[41] F. Morstatter, J. Pfeffer, H. Liu, and K. M. Carley, "Is the sample good enough? comparing data from twitter's streaming api with twitter's firehose," CoRR, vol. abs/1306.5204, 2013.

[42] d. boyd, S. Golder, and G. Lotan, "Tweet, tweet, retweet: Conversational aspects of retweeting on twitter," vol. Proceedings of 43rd Hawaii International Conference on System Sciences, Jan 2010, pp. 1-10.

[43] M. Shumate, A. Pilny, Y. Catouba, J. Kim, M. P. y Lillo, K. Rcooper, A. Sahagun, and S. Yang, "A taxonomy of communication networks," Annals of the International Communication Association, vol. 37, no. 1, pp. 95-123, 2013.

[44] M. Emirbayer and J. Goodwin, "Network analysis, culture, and the problem of agency," American Journal of Sociology, vol. 99, no. 6, pp. 1411-1454, 1994.

[45] H. Taneja and J. G. Webster, "How do global audiences take shape? the role of institutions and culture in patterns of web use," Journal of Communication, vol. 66, no. 1, pp. 161-182.

[46] J. G. Webster, "Program audience duplication: A study of television inheritance effects," Journal of Broadcasting \& Electronic Media, vol. 29, no. 2, pp. 121-133, 1985.

[47] T. B. Ksiazek, "A network analytic approach to understanding cross-platform audience behavior," Journal of Media Economics, vol. 24, no. 4, pp. 237-251, 2011.

[48] M. A. Smith, L. Rainie, B. Shneiderman, and I. Himelboim, Mapping Twitter topic networks: From polarized crowds to community clusters, Pew Research Center, 2014. [Online]. Available: http://www.pewinternet.org/files/2014/02/ PIP_Mapping-Twitter-networks_022014.pdf

[49] A. Saldanha, "Reontologising race: The machinic geography of phenotype," Environment and Planning D: Society and Space, vol. 24, no. 1, pp. 9-24, 2006.

[50] R. Fletcher and R. K. Nielsen, "Are news audiences increasingly fragmented? A cross-national comparative analysis of cross-platform news audience fragmentation and duplication," Journal of Communication, vol. 67, no. 4 , pp. 476-498. 